\title{
Simplified procedures for applying the polymerase chain reaction to routinely fixed paraffin wax sections
}

\author{
P J Coates, A J d'Ardenne, G Khan, H O Kangro, G Slavin
}

\begin{abstract}
The polymerase chain reaction was applied to the analysis of DNA contained in archival paraffin wax embedded material. DNA suitable for the reaction was obtained from these tissues by simple extraction methods, without previous dewaxing of tissue sections. When compared with unfixed material, the reaction efficiency was compromised, so that an increased number of amplification cycles were required to produce equivalent amounts of amplified product. This in turn led to an increase in amplification artefacts, which can be minimised by a simple modification of the standard reaction. Amplification of relatively large DNA fragments was not always successful, and it seems prudent to bear this in mind when designing oligonucleotide primers which are to be used for the amplification of archival material.

The efficiency of the procedure can be improved by dividing the amplification cycles into two parts: this reduces the amount of reagent needed, is relatively simple and inexpensive, and can be performed in one working day.
\end{abstract}

The polymerase chain reaction (PCR) is a method for the in vitro amplification of specific nucleic acid sequences. ${ }^{12}$ The method is based on the use of synthetic oligonucleotides which flank the sequence of interest and act as DNA primers for the enzymatic replication of the defined DNA sequence. Repeated cycles lead to the exponential accumulation of amplified product. The technique is therefore able to produce large amounts of product from small samples.

In histopathology the most important aspect of the technique is its ability to amplify the impure, fragmented DNA found in routinely fixed and processed wax block specimens. DNA may be extracted from these tissues by proteolytic digestion and further purification, $^{3}$ or DNA may be amplified directly from a previously dewaxed section. ${ }^{45}$ Analysis of results from a standard reaction involves hybridisation with radiolabelled probes, ${ }^{34}$ or an increase in the number of cycles performed allows simpler, less hazardous methods to be used. ${ }^{6}$
We are interested in identifying DNA sequences in paraffin wax embedded tissues as an aid to the diagnosis of viral infection, and in studies to investigate the possible role of certain viral and cellular genes in human malignant disease. To this end we wish to develop a method which can be introduced easily into a diagnostic histopathology laboratory. We have investigated several different aspects of the polymerase chain reaction which are specifically relevant to the use of paraffin wax material.

The main aim of these studies was to provide simple methods for the preparation of DNA and the analysis of amplified products. We therefore focused our efforts on applying the polymerase chain reaction to DNA extracted by simple boiling of wax sections. One problem which we encountered when using material prepared in this manner was the presence of "primer-dimer" artefact, which occurs in the presence of poor quality starting material, ${ }^{\top}$ and it was our aim to lessen or prevent this.

As a model system for our studies, we amplified two different sized fragments of the human $\beta$-globin gene to study the maximum size of fragment which can be reliably amplified from paraffin wax material. The method was then used to identify the presence of Epstein-Barr virus (EBV) in tissue culture cells infected with EBV, and in sections of undifferentiated nasopharyngeal carcinomas.

\section{Methods}

Human cytomegalovirus, varicella-zoster virus, or herpes simplex virus were grown in cultures of human embryonic fibroblasts. B958 cells (an infective EBV cell line) and Namalwa cells (containing one or two copies of EBV per cell) were grown as suspension cultures. In each case DNA was extracted by boiling $5 \mu \mathrm{l}$ of culture diluted to $50 \mu \mathrm{l}$ in distilled water for 10 minutes.

Nine cases of undifferentiated nasopharyngeal carcinoma were examined. All tissues had been removed during surgery and immersion fixed in $10 \%$ formol-saline before processing to paraffin wax on an automatic tissue processor according to standard histological procedures. Sections were cut on a microtome and collected into $1.5 \mathrm{ml} \mathrm{microcentrifuge} \mathrm{tubes.}$

EXTRACTION OF DNA

We examined four different methods for the 
extraction of DNA from paraffin wax sections of the samples:

Method 1 A single $5 \mu \mathrm{m}$ section was dewaxed in xylene, washed in alcohol, and dried. The section was resuspended in $50 \mu \mathrm{l}$ of sterile distilled water and boiled for 10 minutes. The amplification buffer was then added directly to the boiled section. ${ }^{4}$

Method 2 Single $5 \mu \mathrm{m}$ sections were collected from each sample. Sections were resuspended in $50 \mu \mathrm{l}$ sterile water and boiled directly, without previous xylene and alcohol treatment. Amplification buffer was added directly to the boiled section.

Method 3 Four $10 \mu \mathrm{m}$ sections were collected in a single tube, dewaxed in xylene, washed in alcohol, and dried. Sterile distilled water $(300$ $\mu \mathrm{l})$ was added and the tubes were boiled for 15 minutes. Tissue debris was removed by centrifugation and the supernatant stored at $-20 \mathrm{C}$ in a clean tube. ${ }^{8}$ Aliquots of $30 \mu \mathrm{l}$ were used for each amplification reaction.

Method 4 As in method 3, groups of four 10 $\mu$ m sections were collected and boiled for 15 minutes in $300 \mu \mathrm{l}$ sterile water, but without previously dewaxing the sections. The tubes were cooled and centrifuged, and the tissuefree supernatant was stored at $-20^{\circ} \mathrm{C}$. Aliquots of $30 \mu \mathrm{l}$ were used for each reaction.

For each extraction method, a negative control was included, in which no tissue was added to the tube.

\section{OLIGONUCLEOTIDE PRIMERS}

Oligonucleotides were synthesised using the $380 \mathrm{~B}$ or 391 DNA synthesisers from Applied Biosystems (Warrington, Cheshire). Oligonucleotides were fully deprotected after synthesis, precipitated in ethanol, and used without further purification. Sequences are given from $5^{\prime}$ to $3^{\prime}$.

BGLO1 ACACAACTGTGTTCACTAGC

BGLO2 CAACTTCATCCACGTTCACC

BGLO3 ATGGTGCACCTGACTCCTGAGG

BGLO4 GCCATCACTAAAGGCACCGAGC

EBVW 1 CACTTTAGAGCTCTGGAGGA

EBVW2 TAAAGATAGCAGCAGCGCAG

Sequences for amplification of the $\beta$-globin gene are taken from published data. BGLO1 combined with BGLO2 amplify a 110 base pair (bp) segment, ${ }^{1}$ while BGLO3 and BGLO4 amplify a 355 bp fragment. ${ }^{6}$ The EBV primers were designed from the published sequence of the EBV genome, ${ }^{9}$ and flank a 153 bp piece of the $B a m H 1^{\prime}$ ' $W$ ' internal repeat sequence.

\section{POLYMERASE CHAIN REACTION}

The reaction was performed essentially as described $^{2}$ using the heat stable enzyme, Thermus aquaticus (Taq) DNA polymerase (Perkin-Elmer Cetus), and following the instructions supplied with the enzyme. All reagents were prepared in sterile distilled water, and autoclaved tubes and pipette tips were used throughout.

The reactions were carried out in a total volume of $100 \mu \mathrm{l}$, in sterile $1.5 \mathrm{ml} \mathrm{micro-}$ centrifuge tubes. An appropriate volume of amplification buffer was added to each DNA sample, to give final concentrations of $10 \mathrm{mM}$ TRIS-HCl (pH 8.3); $50 \mathrm{mM} \mathrm{KCl,} 1.5 \mathrm{mM}$
$\mathrm{MgCl}_{2}, 0.01 \%$ gelatin, $0.2 \mathrm{mM}$ of each deoxynucleotide and $0.5 \mu \mathrm{M}$ of each oligonucleotide primer. Two and a half units of Taq polymerase per tube were also included, and the reactions covered with mineral oil to prevent evaporation. Negative control reactions were performed with each batch of reactions, comprising tubes containing distilled water in place of the DNA samples.

The polymerase chain reaction was performed using an automatic temperature cycler (Techne UK Ltd, Cambridge), and sequential samples were subjected to two different procedures.

\section{Standard procedure}

Samples were amplified through 30,40 , or 50 consecutive cycles. Each amplification cycle consisted of a denaturation step at $94^{\circ} \mathrm{C}$ for one minute, primer annealing at $60^{\circ} \mathrm{C}$ for 30 seconds, and extension at $72^{\circ} \mathrm{C}$ for one minute. Cycles were preceded by two minutes at $94^{\circ} \mathrm{C}$ to ensure full denaturation of the target DNA, and were followed by an extra five minutes at $72^{\circ} \mathrm{C}$ after the final cycle to ensure full extension of product.

\section{Modified amplification procedure}

As an adaptation of the standard reaction outlined above, we performed a two stage procedure, in which samples were subjected to an initial 25 cycles of amplification in the presence of lesser amounts of oligonucleotide primer $(0.05 \mu \mathrm{M})$ and Taq polymerase $(0.25$ units). Aliquots of $5 \mu \mathrm{l}$ were then removed and added to $95 \mu \mathrm{l}$ of fresh amplification buffer containing $0 \cdot 25 \mu \mathrm{M}$ of each oligonucleotide and one unit of Taq polymerase. Samples were then subjected to a further 25 cycles of amplification.

\section{GEL ANALYSIS}

In all cases the completed reactions were analysed by electrophoresis of a $10 \mu \mathrm{l}$ aliquot through a 3\% agarose gel (Sigma UK Ltd). After electrophoresis gels were stained with ethidium bromide and examined on an ultraviolet light transilluminator. ${ }^{10}$ Bands of the appropriate size were identified by comparison with DNA markers of known molecular weight (Sigma UK Ltd).

\section{Results}

EFFECTIVENESS OF PRIMERS IDENTIFYING EBV IN TISSUE CULTURE CELLS

When using tissue culture cells, the EBV primers produced successful amplification of two different EBV positive cell lines, producing the $153 \mathrm{bp}$ fragment predicted from the sequence data. Amplification of these samples was clearly visible after 30 amplification cycles. Cells infected with other human herpes viruses gave no amplification with these primers.

EFFECTIVENESS OF PARAFFIN WAX TISSUES

The demonstration of $\beta$-globin sequences was used to ascertain the effectiveness of the DNA extraction methods used. When using tissue culture cells, amplification products were 


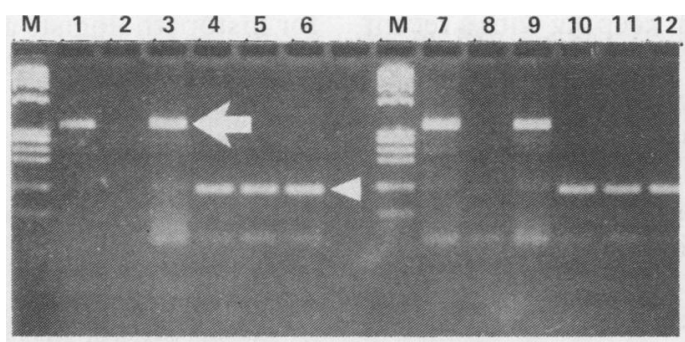

Figure $1 \quad P C R$ amplification of the $\beta$-globin gene from paraffin wax sections of three nasopharyngeal cancers. Lanes 1-3 and 7-9 show amplification of the $355 \mathrm{bp}$ fragment (arrow); lanes 4-6 and 10-12 show amplification of the $110 \mathrm{bp}$ fragment (arrowhead). The $D N A$ used in lanes 1-6 was extracted by method 3; the DNA used in lanes 7-12 was extracted by method 4. Note that the second sample analysed shows no amplification of the 355 bp fragment (lanes 2 and 8), although amplification of the $110 \mathrm{bp}$ fragment was successful (lanes 5 and 11). $M=D N A$ markers (HaeIII digest of pBR322).

easily visible after 30 cycles of amplification. Using wax sections, however, 50 cycles had to be performed to achieve any visible amplification product. Even after 50 cycles amplification of the $355 \mathrm{bp} \beta$-globin fragment was not visible in one of the nine samples, no matter which of the four different extraction methods had been used (fig 1). This finding suggests that amplification of large genomic fragments may be compromised from certain samples prepared by these simplified extraction methods. In contrast, amplification of the shorter $110 \mathrm{bp}$ fragment of the same gene showed clear amplification products from all samples, regardless of the method used for extraction (fig 1).

Because methods which do not require prior dewaxing of the tissue are simpler to perform, we concentrated on using DNA extracted in the supernatant of boiled, undewaxed sections (method 4). Using this method, amplification of the $153 \mathrm{bp}$ EBV fragment was positive in every case (fig 2). No specific amplification bands were seen in any of the negative control samples.

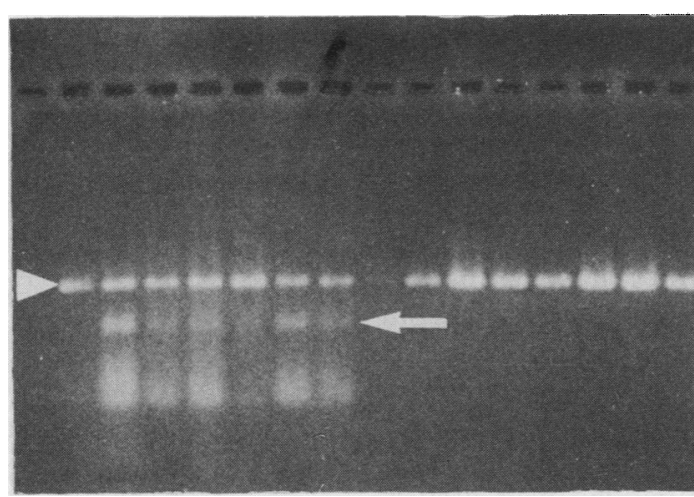

Figure 2 PCR amplification of a 153 bp fragment of $E B V$ from seven nasopharyngeal cancers. The left side of the photograph shows the results obtained after 50 consecutive cycles of amplification. The right side of the photograph shows the results after performing the reaction in two sets of 25 cycles. The specific amplification product at $153 \mathrm{bp}$ is denoted by an arrowhead. Note also the presence of lower molecular weight bands (primer-dimer artefact) in many of the samples on the left, which were subjected to 50 consecutive cycles (arrow). This amplification artefact is absent in the corresponding set of samples amplified by the modified procedure, and the specific reaction product is more intense in many of these samples.
MODIFIED PROTOCOL TO AVOID AMPLIFICATION ARTEFACTS

When performing these reactions, we observed the presence of large amounts of "primerdimer" artefact, which appeared in many of the reactions after 50 cycles. This amplification artefact was avoided by an amplification procedure of two stages of 25 cycles each. As a consequence of reducing artefacts, the revised protocol improves reaction efficiency, and thereby reduces the amounts of reagents required. Furthermore, these reactions provided more intense bands on agarose gels (fig 2).

\section{Effectiveness of modified protocol}

Using this modified protocol, we were able to amplify the $110 \mathrm{bp}$ fragment of the $\beta$-globin gene from each of the nine samples of nasopharyngeal carcinoma. Amplification of EBV was also successful in each case. Amplification of the larger, $355 \mathrm{bp}$ fragment of EBV, however, was still unsuccessful in one of the nine samples. To investigate this further we analysed 29 more archival specimens using this method. We obtained successful amplification of the $110 \mathrm{bp}$ fragment of the $\beta$-globin gene in every case, but were unable to amplify the larger fragment in three of the samples. Thus amplification of the $355 \mathrm{bp}$ fragment was unsuccessful in a total of four out of $38(10.5 \%)$ paraffin wax samples.

\section{Discussion}

The polymerase chain reaction has a great potential for the genetic analysis of tissues. ${ }^{11}$ These include rapid prenatal diagnosis of inherited diseases, ${ }^{112}$ detection of residual leukaemic disease, ${ }^{13} 14$ detection of clonality in lymphoproliferative lesions, ${ }^{15}$ identification of point mutations in cellular proto-oncogenes, ${ }^{1617}$ and the diagnosis of viral infections. ${ }^{1819}$ The polymerase chain reaction has already been used to amplify DNA sequences from 40 year old wax blocks, ${ }^{20}$ and to analyse RNA sequences from paraffin wax tissues. ${ }^{21}$

If the diagnostic potential of the polymerase chain reaction is to be realised methods for performing the technique which can be easily introduced into a diagnostic laboratory must be developed. Previous attempts to perform molecular biological studies using formalin fixed tissues have entailed lengthy purification procedures $^{22-24}$ which would be difficult to perform on a large scale diagnostic basis.

A major attraction of the polymerase chain reaction for histopathologists lies in its ability to amplify poor quality DNA samples obtained by relatively simple methods of extraction. ${ }^{425}$ We have shown that the very simplest methods can produce DNA of sufficient quality for the reaction, and that it is not even necessary to dewax the sections before extracting the DNA. The reaction efficiency is decreased, however, when these methods are used, so that an increased number of amplification cycles is required to compensate for the low yield and poor quality of the DNA template. Even with increased amplification, demonstration of a 355 bp fragment of the $\beta$-globin gene was still not 
reliable. This finding is in keeping with a recent report in which amplification of a 135 bp fragment of the c-K-ras gene was unsuccessful in two of 39 samples analysed, both of which had been removed at necropsy. ${ }^{26}$ These data suggest that the reliable amplification of certain paraffin wax samples may be compromised, possibly due to fixation effects, ${ }^{2026}$ or because of inhibitory substances. ${ }^{627}$

In practice, this restriction is unlikely to affect the use of the reaction on paraffin wax tissues, as long as these limitations are taken into account and oligonucleotides are designed to amplify only relatively short DNA sequences. Indeed, we were able to amplify a $110 \mathrm{bp}$ sequence of the $\beta$-globin gene from samples which did not permit amplification of a larger fragment of the same gene. Alternatively, if it is necessary to amplify larger fragments digestion of sections with proteinase $\mathrm{K}$ can be used to produce higher quality template DNA than is achieved by simple boiling. ${ }^{25}$

Another problem which we encountered when applying the reaction to paraffin wax tissues is the formation of "primer-dimer" artefact, which occurs when many consecutive cycles of amplification are performed. Primerdimers probably result from random extension of the oligonucleotide primers, such that they become complementary to each other and act as templates for the DNA polymerase. ${ }^{7}$ Factors which favour the formation of primer-dimers include small amounts of starting template DNA, high concentrations of oligonucleotide primers, and high enzyme activities. Once primer-dimers begin to form, amplification of these short sequences is rapid and may become the major reaction, swamping amplification of the desired sequence. ${ }^{\text {? }}$

To avoid the problems associated with the formation of primer-dimers we divided the standard reaction into two separate parts. In the first set of cycles the concentrations of oligonucleotide primers and DNA polymerase are intentionally kept low, so that the production of randomly extended primers is minimal. Subsequent amplification proceeds more efficiently, as the amount of DNA template available has been increased, while most primers in the reaction mixture are only subjected to 25 amplification cycles and are unlikely to be extended to the point at which dimerisation can occur. We found that our method does indeed permit reliable amplification with reduced reagent expenditure, but without adding greatly to the complexity of the method.

In conclusion, we have used a simple approach to performing the polymerase chain reaction on routinely embedded wax tissues. We have shown that samples can be prepared by boiling tissue sections, without the need for dewaxing. After 50 cycles of amplification sufficient product is available to permit a simple analysis of the results. The efficiency of the procedure can be improved by dividing the amplification cycles into two parts, which also reduces the amount of reagent needed and provides a relatively simple and inexpensive method, which can be performed within one working day. We believe that the polymerase chain reaction represents a powerful new tool for histopathologists and could in time be used to provide valuable diagnostic information.

We are grateful to Iain Goldsmith and Ian Lamb for oligonucleotide synthesis, and to Peter Crocker for photography. This work was funded by the Cancer Research Committee and the Joint Research Board of St Bartholomew's Hospital. AJ d'A is supported in part by the Imperial Cancer Research Fund.

1 Saiki RK, Scharf S, Faloona F, et al. Enzymatic amplification of $\beta$-globin genomic sequences and restriction site tion of $\beta$-globin genomic sequences and restriction site analysis for diagn

2 Saiki RK, Gelfand DH, Stoffel L, et al. Primer-directed enzymatic amplification of DNA with a thermostable DNA polymerase. Science 1988;239:487-91.

3 Impraim CC, Saiki RK, Erlich HA, Teplitz RL. Analysis of DNA extracted from formalin-fixed, paraffin-embedded tissues by enzymatic amplification and hybridization with sequence-specific oligonucleotides. Biochem Biophys Res Commun 1987;142:710-16.

4 Shibata DK, Arnheim N, Martin WJ. Detection of human papilloma virus in paraffin-embedded tissue using the polymerase chain reaction. J Exp Med 1988;167:225-30.

5 Shibata D, Fu YS, Gupta JW, et al. Detection of human papillomavirus in normal and dysplastic tissue by the papillomavirus in normal and dysplastic tissue by
polymerase chain reaction. Lab Invest 1988;59:555-9.

6 Lo Y-MD, Mehal WZ, Fleming KA. In vitro amplification of hepatitis $B$ virus sequences from liver tumour DNA and from paraffin wax embedded tissues using the polymerase chain reaction. J Clin Pathol 1989;42:840-6.

7 Saiki RK. The design and optimization of the PCR. In: Erlich HA, ed. PCR Technology. Principles and applications for DNA amplification. New York: Stockton Press, 1989:7-16.

8 Griffin NR, Bevan IS, Lewis FA, Wells M, Young LS. Demonstration of multiple HPV types in normal cervix and in cervical squamous cell carcinoma using the polymerase chain reaction on paraffin wax embedded material. J Clin Pathol 1990;43:52-6.

9 Baer R, Bankier AT, Biggin Pl, et al. DNA sequence and expression of the B95-8 Epstein-Barr virus genome. Nature 1984;310:207-11.

10 Maniatis T, Fritsch EF, Sambrook J. Gel electrophoresis of DNA. In: Molecular cloning. A laboratory manual. 2nd Ed. New York: Cold Spring Harbor Laboratory Press, 1989:6:3-6:19.

11 Eisenstein BI. The polymerase chain reaction. A new method of using molecular genetics for medical diagnosis. $N$ Engl J Med 1990;322:178-82.

12 Kogan SC, Doherty M, Gitschier J. An improved method for prenatal diagnosis of genetic diseases by analysis of amplified DNA sequences. $N \mathrm{Engl} \mathrm{J} \mathrm{Med} \mathrm{1987;317:}$ 985-90.

13 Lee MS, Chang KS, Cabanillas F, et al. Detection of minimal residual cells carrying the $t(14 ; 18)$ by DNA minimal residual cells carrying the $t(14 ; 18)$ by

14 Morgan GJ, Janssen JWG, Guo AP, et al. Polymerase chain reaction for detection of residual leukaemia. Lancet 1989; i:928-9.

15 McCarthy KP, Sloane JP, Wiederman LM. Rapid method for distinguishing clonal from polyclonal $\mathrm{B}$ cell populations in surgical biopsy specimens. J Clin Pathol 1990;43:429-32.

16 Haliassos A, Chomel JC, Tesson L, et al. Modification of enzymatically amplified DNA for the detection of point mutations. Nucleic Acids Res 1989:17:3606.

17 Jiang W, Kahn SM, Guillem JG, Lu SH, Weinstein IB. Rapid detection of ras oncogenes in human tumors: applications to colon, esophageal, and gastric cancer. Oncogene 1989;4:923-8.

18 Laure F, Rouzioux C, Veber F, et al. Detection of HIV DNA in infants and children by means of the polymerase chain reaction. Lancet 1988;ii:538-41.

19 Demmler GS, Buffone GJ, Schimbor CM, May RA. Detection of cytomegalovirus in urine from newborns by using polymerase chain reaction amplification. J Infect $D i$ 1988;158:1177-84.

20 Shibata D, Martin WJ, Arnheim N. Analysis of DNA sequences in forty-year-old paraffin-embedded thintissue sections: A bridge between molecular biology and classical histology Cancer Res 1988;48:4564-6.

21 Jackson DP, Quirke P, Lewis F, et al. Detection of measle virus RNA in paraffin-embedded tissue. Lancet 1989; i:1391.

22 Goelz SE, Hamilton SR, Vogelstein B. Purification of DNA from formaldehyde fixed and paraffin embedded human from formaldehyde fixed and paraffin embedded human
tissue. Biochem Biophys Res Commun 1985;130:118-26.

23 Dubeau L, Chandler L, Gralow JR, Nichols PW, Jones PA Southern blot analysis of DNA extracted from formalinfouthern blot analysis of DNA extracted from formalin

24 Warford A, Pringle JH, Hay J, Henderson SD, Lauder I. arford A, Pringle JH, Hay J, Henderson SD, Lauder I.
Southern blot analysis of DNA extracted from formolsaline fixed and paraffin wax embedded tissue. $J$ Pathol saline fixed and par

25 Jackson DP, Lewis FA, Taylor GR, Boylston AW, Quirke P Tissue extraction of DNA and RNA and analysis by the polymerase chain reaction. J Clin Pathol 1990;43. 499-504.

26 Rogers BB, Alpert LC, Hine EAS, Buffone GJ. Analysis of DNA in fresh and fixed tissue by the polymerase chain reaction. Am J Pathol 1990;136:541-8.

27 De Franchis R, Cross NCP, Foulkes NS, Cox TM. A potent inhibitor of Taq polymerase copurifies with human genomic DNA. Nucleic Acids Res 1988;16:10355. 